\title{
The technologisation of childhood? Young children and technology in the home
}

\author{
Lydia Plowman, Joanna McPake, Christine Stephen \\ Institute of Education, University of Stirling
}

\begin{abstract}
Plowman L, McPake, J., Stephen C. (2010). The technologisation of childhood? Young children and technology in the home. Children and Society 24 (1) 63-74.
\end{abstract}

\begin{abstract}
We describe an eighteen-month empirical investigation of three- and four-year-old children's uses of technology at home, based on a survey of 346 families and 24 case studies. The findings are reported in the context of social commentators' anxieties about the ways in which childhood is being transformed by technology. Although we report evidence of some parental disquiet about the role of technology in children's lives we illustrate some of the complexities in families' attitudes to, and uses of, technology and conclude that it is not perceived by parents to be the threat to modern childhood that is claimed.
\end{abstract}

\section{The debate}

The increasing pervasiveness of technology has led to public debate about its role in the lives of young children. This debate gives prominence to the expression of anxieties about the ways in which childhood is being transformed by technology, often claiming that children's cognitive, emotional and social development is under threat. The discussion is usually focused on the dominance of screen-based media (such as television, games consoles and computers) in children's lives and how this leads to a number of ills, including social isolation and obesity. In her introduction to a report on the risks children face from the internet and video games, Byron (2008, p.1) refers to a 'fiercely polarised debate in which panic and fear often drown out evidence'. The study reported here enables us to bring some evidence to this discussion, showing that these anxieties are not as widespread amongst parents as media coverage leads us to believe.

Until recently, the debate had found strongest expression in the United States. The American Academy of Pediatrics' Committee on Public Education has published guidelines on young children's exposure to the media and recommends, inter alia, that pediatricians should urge parents to: avoid television viewing for children under the age of two, make children's rooms 'electronic media-free environments' and resist using the media as electronic babysitters. In the interests of being good role models they suggest that pediatricians should limit the use of television and videos in patients' waiting rooms and provide educational materials to promote reading (American Academy of Pediatrics' Committee on Public Education, 1999, p.342). They have also warned against the effects of media violence in television programmes, music and video games (2001).

In Fool's Gold: A Critical Look at Computers in Childhood (Cordes and Miller, 2000) the Alliance for Childhood called for an immediate moratorium on the further introduction of computers in early childhood, except for special cases of students 
with disabilities. It recommended a refocusing on 'the essentials of a healthy childhood' (such as play, reading books and 'hands-on experiences of nature and the physical world') and urged the Surgeon General to produce a report on the hazards computers pose to children. It was followed by Tech Tonic: Towards a New Literacy of Technology (Alliance for Childhood, 2004) which described technology as responsible for irreversible changes in human biology and the world's ecology and claimed that:

the damage being done by immersing children in electronic technologies is becoming clearer. Increasing numbers of them spend hours each day sitting in front of screens instead of playing outdoors, reading, and getting much-needed physical exercise and face-to-face social interaction-all of which, it turns out, also provide essential stimulation to the growing mind and intellect. (p.1)

The report promoted education as a means of inspiring and preparing children to protect the world's ecology and make wise choices in the future, stating that 'It is time for concerted citizen action to reclaim childhood for children' (p.1). Other concerns are voiced by those such as Bruner \& Bruner (2006, p. xxi) who refer to video games as the digital drug' and warn parents of the dangers of addiction.

Buckingham (2000) describes positions such as these as adopting a 'death of childhood' thesis in which it is believed that childhood has been lost as a result of changes in modern society. Postman (1982/1994), for instance, refers to technology as causing the disappearance of childhood. Fuelled by a combination of panic and nostalgia, fears about young children's use of technology have persisted over the last few decades and exist in a melange of undifferentiated anxieties about childhood. An example of this convergence of childrearing concerns in the UK is found in a letter published in the Daily Telegraph newspaper (Abbs and others, 2006) with over one hundred signatories, including well-known children's authors, academics and clinicians. Headed 'Modern life leads to more depression among children' it went on to say:

Since children's brains are still developing, they cannot adjust - as fullgrown adults can - to the effects of ever more rapid technological and cultural change. They still need what developing human beings have always needed, including real food (as opposed to processed 'junk'), real play (as opposed to sedentary, screen-based entertainment), first-hand experience of the world they live in and regular interaction with the reallife significant adults in their lives.

This letter prompted widespread commentarys in the media and the metaphor of a 'toxic childhood', used in the eponymous book (Palmer, 2006) which coincided with the letter's publication, became strongly associated with this debate. The book, the sub-title of which is 'How the modern world is damaging our children and what we can do about it', includes sections on additives in food, the decline of family mealtimes and good manners, the lack of outdoor play and changes in children's sleeping habits. The two chapters on the effects of new technologies include statements such as:

Many [children] spend at least as much of their leisure time on screen- 
based activities as they do with the real people in their lives. So what children watch on TV, film and DVD and what they do on computers and console games clearly affects their development. (Palmer, 2006, p.227)

The focus of these concerns is often on young children because they are seen as innocent and particularly vulnerable in the early stages of development. Healy (1998), for instance, claims that the early years are a 'busy time for the brain' and that using computers before the age of seven subtracts from important developmental tasks. Others, such as Palmer (op. cit.), claim that children's linguistic development is at risk because they spend too much time listening to television (receptive language) and not enough time talking with others (productive language). A commonly held, but often implicit, position is that technology is necessary for adults' leisure time and working lives but it is unsuitable for young children owing to this perceived threat to childhood. Older children are in a more ambivalent position than the young children involved in this study as there is widespread agreement that digital technologies support study and act as a preparation for work. This perspective often underlies the views of commentators who consider that technology such as computer and video games, television or the internet can make a key contribution to older children's social and intellectual development (Gee, 2003; Green and Hannon, 2007; Johnson, 2006; Prensky, 2006; Shaffer, 2007).

There is increasing support for this standpoint, although it is often tempered by reservations about the ways in which government has made technology central to its aims of training children for the knowledge economy (Selwyn, 2003) and concerns about the long-term implications of the digital divide. Although these views have some prominence in the academy, particularly in terms of an increasing body of work on digital literacies, creativity and participatory cultures (Jenkins and others, 2006; Marsh, 2005; McPake and others, 2008), they tend not to have the same persuasiveness in the popular media. The parents involved in our study were certainly more aware of the arguments about the dangers of technology than its creative potential. Different key concerns are expressed with varying degrees of persuasiveness, but the arguments of those who see the technologisation of children's lives through television, computers and games consoles as threatening can be distilled into three broad categories:

Socioculural

- Children's social development is at risk because children play alone.

- Technology provides virtual, second-hand, screen-based experience rather than real, first-hand experience.

- The marketing of technological products is insidious and preys on vulnerable children.

Cognitive

- Children's intellectual development is at risk due to the demands made on cognitive resources.

- The development of children's imagination is inhibited because technology encourages passivity.

- Children's linguistic development is inhibited.

Wellbeing

- Children spend time indoors that would be better spent outdoors.

- Children's health is endangered because sedentary use increases the risk of obesity. 
- The technologies are addictive.

There is a risk of exposure to unsuitable content.

- Opportunities for interactions with family members that promote emotional development are reduced.

This forms the backdrop to our study. Its central aim was to investigate socioeconomic disadvantage and young children's developing competences with technologies in their homes (McPake and others, forthcoming) but our data has enabled us to consider the arguments outlined above relating to the technologisation of childhood and to draw some different conclusions.

\section{Young children's uses of technology}

Entering e-Society: Young children's development of e-literacy, finished in spring 2007. A survey was distributed to families with three- and four-year-old children in ten preschools located in small towns, semi-rural settings and urban areas of multiple deprivation in central Scotland. It produced 346 responses, a response rate of $43 \%$. The study was informed by a sociocultural approach that recognised that family practices should be analysed within a framework that encompasses social and cultural dimensions. In its investigations of parents' attitudes to technology it drew on the concept of parental ethnotheories (Brooker, 2003; Harkness \& Super, 1995), or cultural belief systems. In Brooker's study (ibid.), parental beliefs about childhood, the home, literacy and learning are used to interpret variations in the child's school experiences, and her interviews with parents of four-year-olds and observation of family practices 'revealed strong but sometimes unconscious cultural assumptions about good parenting' (p.119). In our study, these ethnotheories were generally based on parents' earlier experiences of technology at school, further education or work, as well as public debate about the role of technology in the lives of young children.

Much of the data for this study was reported rather than based on observation and was therefore privileging the parents' perspectives over the researchers'. This is more direct than inferring attitudes and past experiences from behavioural observations but does not provide many opportunities to establish whether there was variance between parents' espoused views and their day-to-day practices. The study drew on three main types of evidence: the audit provided by the survey, the interviews with families in their own homes, and conversations with children. We also observed and videoed children using various self-selected items on an opportunistic basis.

\section{The case studies}

The survey provided basic demographic data which was used to compare more and less affluent households and to select 24 case-study families to represent different socioeconomic status. We described families with household income of over $£ 20 \mathrm{k}$ pa as 'advantaged' and those with income less than this as 'disadvantaged'. Different levels of technology were assessed based on ownership of a computer with internet access, mobile phone and interactive television. 'Low technology' families had fewer of these items, although new acquisitions were made over the duration of the visits. By the end of the period of research, in early 2007, only one family did not have a computer with internet access.

'Low technology' did not necessarily correlate with low household income. We 
categorised 13 families as advantaged and 11 as disadvantaged; 13 families as 'high technology' and 11 as 'low technology', distributed as shown in Table 1. Five families dropped out of involvement in the study at various stages and four of these were in the 'disadvantaged' category. At the start of the study seven children were three years old, sixteen were four years old, and one child was five.

\begin{tabular}{|l|c|c|}
\hline & Advantaged & Disadvantaged \\
\hline High technology & 9 & 4 \\
\hline Low technology & 4 & 7 \\
\hline
\end{tabular}

Table 1: Distribution of case-study families

Multiple visits to case-study families over five rounds of data collection gave us the opportunity to gain an understanding of family cultures, develop relationships of trust and check our emergent findings. Although the children were often present during our interviews with their parents we did not seek to involve them directly until the third round. Our approach was designed to reflect our understanding that children have valuable perspectives on their experiences and we devised activities intended to appeal to them, had face validity for the children and their parents, and were within the children's existing behavioural repertoires (Stephen and others, forthcoming).

Our analyses of the case study data used NVIVO for detailed case-by-case readings of the data and focused on:

- why families chose to purchase particular technologies

patterns of use within the family

perceived educational benefits of children's use of these technologies

the influence of parents' own experiences of technologies on the opportunities

they provided for their children

- children's developing digital literacy over the lifetime of the project

- parents' changing perspectives on their children's developing interests and expertise.

In our earlier studies with pre-school children (Plowman and Stephen, 2005, 2007) we defined digital technologies broadly to include musical keyboards, remote controls, games consoles and toys that simulate devices such as mobile phones and laptops. The emphasis of this study was on digital connectivity (ie use of the internet, interactive television and mobile phones) so we mainly report here on children's use of these items, although we also refer to the broader technological landscape.

\section{Availability of technology}

At the time of the survey in 2005 almost all the children aged three or four were growing up in homes in which a range of digital technologies were in use. However, presence in the home did not necessarily mean availability to the children and the range of technologies was not principally determined by economic factors, although internet access was unequally distributed: while over four fifths $(82 \%)$ of the more advantaged families had access, just over half (56\%) of the less advantaged respondents did so. Most of our survey respondents' children were living in households where there was access to a mobile phone (98\%), interactive TV $(75 \%)$ 
and a computer with internet access (69\%). Two-thirds (64\%) of those living in homes with an internet connection made use of it for looking at websites; for most of the children this was with adult supervision, although $10 \%$ of them used websites on their own. About half of the children (48\%) used a mobile phone, typically with adult help, and a similar proportion (56\%) used interactive television.

By the time they were ready to start school, most of our case-study children had experience of using a broad range of technologies in their own homes and those of friends and relatives, including telephones, computers, electronic musical instruments, MP3, CD or cassette players, televisions, video and DVD players, still or video cameras, and games consoles.

\section{Family practices}

All children in our case studies had different play preferences and the role of technology in this play varied depending on availability, parental attitudes and individual disposition. Whether high or low users of technology, all children engaged in a range of other activities such as small world play, dressing up, outdoor play, or arts and crafts. Sometimes these activities blended seamlessly: one boy liked to download and print images of characters from Lord of the Rings websites, stick them onto cardboard, cut them out and then role play with them alongside 3D toys of characters from the film.

Practices such as purchasing decisions, the kinds of technologies which children were allowed to use and the balance struck between technological and traditional toys and activities were influenced not so much by income as by family values. Parents were not necessarily explicitly concerned with learning outcomes derived from technological activities (although they often became more aware of educational potential as their child's transition to school became imminent) but they had an interest in supporting the development of operational skills such as finding specific websites so that their children could become independent users and occupy themselves. Parents also taught children to use a television remote control for the same purpose (it was described as 'mum and dad's best friend' by one parent). Whilst some television programmes were seen to have learning value they felt less guilty about using the computer to fulfil this function because the act of using it was perceived to be educational: only $9 \%$ of parents responding to the survey disagreed with the statement ' $I$ expect the internet to play an important part in my child's education' and playing with the computer was seen as a preparatory activity.

Communication and relationships between family members and friends were supported by sharing digital images: a common experience for most of the children in our studies was to look at photographs and videos taken of them since they were babies. Sent to distant friends and relatives or shared within the family these images were used as a focus for conversation, helping the child to construct an identity as son or daughter, grandchild, nephew, niece, or cousin and to develop a sense of their own life histories. Children were also beginning to use the cameras for themselves.

Some families were enthusiastic users of technology and parents in these homes encouraged their children's engagement with computer games, webcams or internet sites such as Nick Jr or CBeebies. In these families, children's developing competences with technology were noted with pride and seen as necessary for a successful future. In some homes, more traditional activities were highly valued and 
parents encouraged imaginative games with dolls or outdoor play. Some of these parents said that they were not against new technologies but rather that they would wait until their child was ready or interested.

All of the children in our case-study families engaged in an extensive range of nontechnological activities. All but four reported going to the park as one of their favourite activities, nearly all children regularly played outside in the street or garden and more than half liked to go swimming. For some children, technology did not feature in their favourite activities at all. Although we have indicated the ways in which children's behaviour is shaped by family practices and parental ethnotheories our evidence suggests that their individual preferences and enduring interests and dispositions are important influences too and children were discriminating users of technology (Stephen and others, forthcoming). Children who lived in 'high technology' homes were not necessarily drawn to use these resources, regardless of the activities or invitations of their parents or siblings.

\section{Parental attitudes}

Across these case-study families, there was no clear divide in attitudes between those who were economically advantaged or disadvantaged or even, in many cases, between 'high technology' and 'low technology' families. We found a stronger link between parents' own experiences of technology and how this influenced the opportunities they offered their children (McPake and others, forthcoming). On our second visit to the families participants were asked to respond to a set of statements which had been derived from our earlier interviews or media commentary and presented on laminated cards. Parents' responses indicated that they had some concerns about their children's uses of technology but considered that their child was not at risk if they were used in moderation and with appropriate levels of supervision.

Whilst a quarter of the parents agreed with the statement 'Using some kinds of technology can be damaging to children's health and development', most were uncertain and took the opportunity to discuss some of their concerns. Their comments referred to mobile phones, computer games and televisions and the most frequently cited anxieties were about health and physical development, with some concerns about the impediment to social interaction and exposure to inappropriate content. However, the key feature of these responses was the extent to which they were characterised by reservations and uncertainty ('studies say contradicting things', 'everything has its place in moderation', 'both agree and disagree') and the occasional difference of views between the mother and the father. This equivocation was also found when parents were presented with the statement 'Playing on the computer or PlayStation is just harmless fun' as broad agreement was qualified ('yes, to a certain degree', 'yes - if not for too long', 'yeah, as long as they're not doing it all day') and there were some comments about the need for regulation ('fine within limits', 'not more than one or two hours in one go').

The same statements were used on two different occasions about fifteen months apart so that we could establish whether views altered. This period was characterised by many changes, both in the child's development, the family environment (changes of jobs or housing, new siblings, new acquisitions) and the external technological landscape (increasing availability of broadband). By the second occasion there was less uncertainty and more polarisation of views. The balance had shifted to greater 
caution, perhaps reflecting the children's increased independence and, in some cases, ability to enter or read text but responses about use of the computer or games consoles were still qualified ('with parental controls', 'as long as it has its place', 'within reason', 'as long as it's limited', 'depending on how it is used and how much time it is used for').

\section{Regulation}

As these responses indicate, parents became more aware of potential problems as their children got older and they began to take steps to regulate use. Their main concerns were to achieve balance in their child's activities, introduce (at least notional) time limits and ensure some level of supervision. About a third of the casestudy children were keen users of technology, such as playing games on websites or games consoles, or watching television or DVDs. In response to the statement 'Playing computer games is one of my child's favourite activities' a third of parents agreed and a half of parents disagreed, with a slight increase in the numbers enjoying computer games by the end of the visits. None of the children was using technologies to a degree that worried parents.

Nevertheless, all families, apart from one, agreed with the statement 'If children are playing with interactive toys, electronic games or new technologies they are missing out on more important activities'. The solution for the vast majority was to balance the amount of time spent on different pursuits, but parents were also keen to ensure an even distribution of indoor and outdoor, and solo versus social, activities.

During an interview in the last visit parents were asked if they had made any rules relating to their child's use of technology. More than half of the families referred to regulating use of the television but only two mentioned regulating use of the computer: for some, it was not considered necessary because their child had no interest in using it. Rules about watching television were associated with times of the day when it could be watched rather than the duration of viewing sessions and this coincided with scheduling of suitable programmes. Typically children were allowed some time in the morning before going to nursery and some time before and after teatime, with a cut-off point of when they got ready for bed, although in several households the television was on for much of the day as a backdrop to family activities. About half the families allowed children to watch television on their own in their bedrooms, and a couple of the children watched DVDs or video to go to sleep, but some parents only sanctioned viewing as a shared activity in a family room.

Some children needed to gain permission to use the computer or had to be supervised whilst using it and a couple of families limited use of the printer because of the costs of replacement ink cartridges. Where there were rules, use of the computer was restricted by duration rather than time of day, although this was enforced flexibly. A reasonable period of time was typically seen as an hour or so, unless other family members wanted access.

The least ambivalence was found in response to 'I think that we have got the use of new technologies right for our child' as all respondents except one agreed with this statement. The parent who demurred felt that they should provide more for their child: 'I think there are some other things we could provide to give them more opportunities - like handheld games. Perhaps Santa will bring these things.' Prompted by these statements, some parents expressed disapprobation of the extent 
to which others had got it right ('some parents...', 'we would never allow that', 'not our own children') suggesting that, even if these responses were not entirely consistent with their own family practices, they were aware of what would be seen as responsible parenting within the context of debates about children's uses of technology. There was a widespread belief that 'moderation' or 'a sensible balance' would guard against dangers but there was substantial variation in practices from one family to another so the ways in which this was interpreted varied.

Towards the end of the family visits many of the children started school, some were learning to read and write and some families had acquired internet access, computers, new mobile phones or portable DVD players. But the increase in the number of technological devices did not necessarily lead to increased use by the children. For those at school there was less time available for play at home. And as they became more adept at independent play and as their skills at reading, writing and drawing increased, they found other ways of spending their time. Rideout (2007, p.4) found that concern about adverse effects of media increase as children get older so, in time, perhaps these parents will find policing their children's activities more challenging. But, for now, parents mainly felt confident in their abilities to manage the use of technologies.

\section{Discussion}

Childhood experiences often shape how adults act as parents but the technologies currently available for children were not part of their parents' upbringing. The lack of a model to inform this aspect of their parenting means that it is unexplored territory for a whole generation of parents and perhaps accounts for some of their uncertainty. Nevertheless, parents felt that they had things about right. We found no evidence to suggest that the childhoods of these children could be described as toxic or that family life was being undermined. It was not the technologies that determined whether a family communicates, plays together, or supports their child's learning but rather their cultural practices and values. Our analysis indicated that a number of factors which are linked with, but not dependent on, socioeconomic status have a bearing on parental perspectives on young children's uses of technology. Parental ethnotheories were influenced by media discussions but also by parents' educational background and prior experiences of using technologies for work, study or leisure purposes (McPake and others, forthcoming). These findings are in line with recent research which has identified family practices as typically more influential than simple gender or class distinctions in the educational preparation of pre-school children (Vincent and others, 2004).

Our findings on parental attitudes and family practices seem to be consistent with other research. In the UK, a survey of over 1800 parents of children under six (Marsh and others, 2005) found that children were considered to lead generally wellbalanced lives, with popular culture, media and new technologies playing 'an important, but not overwhelming, role in their leisure activities' (p.5). In the United States, Weber (2006) reports findings from a survey of 221 middle-class Caucasian families in which more than $80 \%$ of parents were comfortable or very comfortable with their young children watching television and videos, and comments that parents 'readily accept and even accommodate this trend of infant and toddler media use' (p.172). The Kaiser Family Foundation report (Rideout and Hamel, 2006), based on a series of focus groups and a survey of over one thousand parents with children aged six months to six years old, found that 'Many parents find media a tremendous 
benefit in parenting and can't imagine how they'd get through the day without it' (p.32). Anand and Krosnick (2005) conducted multiple regressions predicting time spent watching television, watching videos/DVDs, reading, playing video games, and using computers using the Kaiser Family Foundation data. They found that parents' education (and marital status, which we did not use as a variable) had significant effects across most types of media use but family income had no impact at all. Although we acknowledge Morrow's (2006, p.94) claim that 'family practices are deeply gendered' we did not find clear differences based on gender for these young children. Rideout and Hamel (2006, p.27) refer to 'only modest differences' in patterns of use for children aged six years or under and Anand and Krosnick (2005) found that gender had only occasional, isolated effects.

There seems to be a disjunction, then, between the case put forward by those warning of the toxic effects of technology and parents' own perceptions. Whilst not a major source of anxiety, many parents were unsure how to respond to what some saw as contradictory accounts reported in the media. Parents were aware of some of the concerns expressed about technologies but they were not troubled by them and nobody was worried about their own child's patterns of use. Nevertheless, the responses to the prepared statements were characterised by uncertainty and, sometimes, inconsistency. Although, overall, parents were happy with the role of technologies in their children's lives they frequently qualified their position or referred to the need for moderation and limits. They used their judgement, sometimes sought advice and sometimes wondered if they had the right balance but generally felt that they were on the right lines. Beliefs that they should regulate their children's use of technology are not surprising given that parents have to supervise many of their young children's activities, including outdoor play (multiple potential dangers), painting and craft activities (messy) and even social encounters with friends (potential disagreements, being led astray). From this perspective, technological play may be seen as safer, in part because it takes place indoors, usually within the parents' peripheral vision (Plowman and others, forthcoming).

The broad range of technologies to which children have access or exposure may suggest that there has been a technologisation of childhood if we ascribe agency to the technology. Such approaches are a response to each generation's fears about cultural change and are generally predicated on a view of children as lacking in agency. Palmer, for instance, refers to a 'technology-driven culture' (2006, p.3) and sees technology, amongst other agents, as responsible for making childhood 'toxic'. This technological determinism is at odds with the findings from our case studies, which suggest that children (and their parents) are active rather than passive users of technology, that an increase in technological items in the home does not necessarily lead to an increase in use by children, and that a range of factors influence the ways in which technology is appropriated within a family setting.

\section{Acknowledgements}

The title of this paper is taken from a small-scale study, The Technologisation of Childhood?, which was funded by the University of Stirling and conducted by Lydia Plowman, Alan Prout and Daniela Sime. Entering e-Society: Young children's development of e-literacy was funded by the ESRC's e-Society programme (RES341-25-0034). We are grateful to Sarah Berch-Heyman and Konstantina Martzoukou and to the children and families who participated in the studies. A development of 
the work reported here, focusing on young children's learning with technological toys in their home environment, has been funded by the ESRC (RES-062-23-0507).

\section{References}

Abbs P and others. 2006. 'Modern life leads to more depression among children'. Letter to the Daily Telegraph, 12 September 2006.

http://www.telegraph.co.uk/news/main.jhtml?xml=/news/2006/09/12/njunk112 $. x m l \& p a g e=1$ [accessed on 21 September 2007]

Alliance for Childhood. 2004. Tech Tonic: Towards a New Literacy of Technology. Alliance for Childhood: College Park, MD.

American Academy of Pediatrics Committee on Public Education. 1999. Media education. Pediatrics 104: 341-343. DOI: 10.1542/peds.104.2.341

American Academy of Pediatrics Committee on Public Education. 2001. Media violence. Pediatrics 108: 1222-1226. DOI: 10.1542/peds.108.5.1222

Anand S, Krosnick J. 2005. Demographic predictors of media use among infants, toddlers, and preschoolers. American Behavioral Scientist 48: 5, 539-561. DOI: $10.1177 / 0002764204271512$

Brooker, L. (2003). Learning How to Learn: Parental ethnotheories and young children's preparation for school. International Journal of Early Years Education, 11 (2), 117-128.

Bruner O, Bruner K. 2006. Playstation Nation: Protect Your Child from Video Game Addiction. Center Street: NY.

Buckingham D. 2000. After the Death of Childhood: Growing Up in the Age of Electronic Media. Polity Press: Oxford.

Byron, T. 2008. Safer Children in a Digital World: The Report of the Byron Review. Department of Children, Schools and Families: Nottingham.

Cordes C, Miller E (eds). 2000. Fool's Gold: A Critical Look at Computers in Childhood. Alliance for Childhood: College Park, MD.

Gee J. 2003. What Videogames have to Teach us about Learning and Literacy. Palgrave Macmillan: New York.

Green H, Hannon C. 2007. Their Space: Education for a Digital Generation. Demos: London.

Harkness, S. \& Super, C. (eds). 1995. Parents' cultural belief systems: Their origins, expressions and consequences. NY: Guilford.

Healy J. 1998. Failure to Connect: How Computers Affect Our Children's Minds. Simon \& Schuster: New York.

Jenkins H, Clinton K, Purushotma R, Robison A, Weigel M. 2006. Confronting the Challenges of Participatory Culture: Media Education for the $21^{\text {st }}$ Century. Macarthur Foundation: Chicago, IL.

Johnson S. 2006. Everything Bad is Good for You: Why Popular Culture is Making us Smarter. Penguin: London.

Marsh J (ed). 2005. Popular Culture, New Media and Digital Literacy in Early Childhood. RoutledgeFalmer: Abingdon, Oxon.

Marsh J, Brooks G, Hughes J, Ritchie L, Roberts S. Wright K. 2005. Digital Beginnings: Young People's Use of Popular Culture, Media and New Technologies. University of Sheffield: Sheffield.

McPake J, Stephen C, Plowman L. 2008. Developing digital literacy at home. American Educational Research Association (AERA) conference, New York, March 2008. 
McPake J, Plowman L, Stephen C. forthcoming. Digitally Divided? An ecological investigation of young children learning to use ICT. Early Childhood Development and Care.

Morrow V. 2006. Understanding gender differences in context: implications for young children's everyday lives. Children and Society 20: 2 92-104. DOI: $10.1111 /$ j.1099-0860.2006.00017.x

Palmer S. 2006. Toxic Childhood: How the Modern World is Damaging our Children and What We Can Do About It. Orion: London.

Plowman L, McPake, J., Stephen C. forthcoming. Just picking it up? Young children learning with technology at home. Cambridge Journal of Education 38 (3).

Plowman L, Stephen C. 2007. Guided interaction in pre-school settings. Journal of Computer Assisted Learning 23: 1 14-21. DOI: 10.1111/j.1365-2729.2007. 00194.x

Plowman L, Stephen C. 2005. Children, play and computers in pre-school education. British Journal of Educational Technology 36: 2 145-158. DOI: 10.1111/j.14678535.2005.00449.x

Postman N. 1982. The Disappearance of Childhood. Vintage Books: NY, revised ed. 1994.

Prensky M. 2006. Don't Bother Me Mom - I'm Learning! Paragon House: St Paul, Minnesota.

Rideout V. 2007. Parents, Children \& Media: A Kaiser Family Foundation Survey. Kaiser Family Foundation: Menlo Park, CA.

Rideout V, Hamel E. 2006. The Media Family: Electronic Media in the Lives of Infants, Toddlers, Preschoolers and Their Parents. Kaiser Family Foundation: Menlo Park, CA.

Shaffer D. 2007. How Computer Games Help Children Learn. Palgrave Macmillan: New York.

Selwyn N. 2003. 'Doing IT for the kids': re-examining children, computers and the 'information society'. Media, Culture and Society 25: 351-378. DOI: 10.1177/0163443703025003004.

Stephen C, McPake J, Plowman L, Berch-Heyman S. (forthcoming). Learning from the Children: Exploring preschool children's encounters with ICT at home. Journal of Early Childhood Research.

Vincent C Ball S \& Kemp S (2004). The social geography of childcare: making up a middle-class child. British Journal of Sociology of Education 25: 2 229-244. DOI: 10.1080/0142569042000205091

Weber D. 2006. Media use by infants and toddlers: A potential for play. In Play=Learning. How Play Motivates and Enhances Children's Cognitive and Socioemotional Growth. Singer D, Golinkoff R, Hirsh-Pasek K (eds). Oxford University Press, New York; 169-191. 